\title{
Research on Acicular Ferrite Nucleation Induced by Inclusions in Pipeline Steel Welding Heat Affected Zone
}

\author{
Jian-Ming WANG ${ }^{1, a}$, Yan LIU ${ }^{2, b, ~}{ }^{*}$, Kai WANG ${ }^{2, ~ c}$, Yang LIU ${ }^{1, d}$ \\ ${ }^{1}$ School of Mechanical Engineering, Shenyang University, Shenyang 110044, China \\ ${ }^{2}$ The Liaoning Provincial Key Laboratory of Advanced Materials \& Preparation Technology, \\ Shenyang University, Shenyang, 110044, China \\ awjmlucky1979@163.com, bliuyanneu@163.com, 'cwkai1991@foxmail.com, \\ dshendacaijialy@126.com \\ ${ }^{*}$ Corresponding author
}

Keywords: Pipeline Steel, Acicular Ferrite, Inclusions, Heat Affected Zone, High Heat Input Welding.

\begin{abstract}
In this paper, the acicular ferrite nucleation induced by inclusions in pipeline steel welding heat affected zone is researched, including the acicular ferrite nucleation induced by the in-situ reaction inclusions, the acicular ferrite nucleation induced by the formed inclusions after the micro-alloying and the micro-mechanism of acicular ferrite nucleation induced by inclusions. The results show that the size of the in-situ reaction inclusion is difficult to control. The use of $\mathrm{A} 1, \mathrm{Nb}$, $\mathrm{Ti}, \mathrm{Ca}, \mathrm{Mg}$ and $\mathrm{Zr}$ alloy oxides and or their composite oxides micro-alloying can promote the nucleation of the intragranular acicular ferrite and can segment the original austenite grains in the interior of the coarse austenite grains effectively, which can improve the strength and toughness of the high heat input welding HAZ significantly. The four kinds of acicular ferrite nucleation mechanism exist mutual contradictions to each other currently. Different inclusions have different mechanism.
\end{abstract}

\section{Introduction}

The demand for oil and natural gas is increasing with the rapid development of the national economy, so the demand of pipeline steel as transportation vector is also increasing. Pipeline transport is an economic, safe and efficient mode of transport, it can not only transport coal and other solid materials, but also can transport oil and natural gas [1]. The research and development of pipeline steel is toward high level development of large-diameter, high pressure and automation with the increase of oil and natural gas transportation capacity and transport distance [2].

In the previous paper, the characteristic of chemical composition of X80 pipeline steel, the microstructure and the existing problems under the condition of high heat input welding were introduced. The micro-alloyed process of $\mathrm{Nb}, \mathrm{Ti}, \mathrm{V}$ elements in X80 pipeline steel and the influence on the mechanical properties were respectively discussed. In addition, the reasons of the grain coarsening in the welding heat affected zone, the softening and brittlement in partial microstructure were explored and the corresponding solutions were presented. Basing on the research work of these scientific issues, the theoretical research system of inclusions induced IAF nucleation should be established. The study can promote the further development and application of the oxide metallurgy technology. The research results have the important engineering significance for the construction of long-distance pipeline transportation system in our country.

Accordingly, the acicular ferrite nucleation induced by inclusions in pipeline steel welding heat affected zone is researched in this paper, including the acicular ferrite nucleation induced by the in-situ reaction inclusions, the acicular ferrite nucleation induced by the formed inclusions after the micro-alloying and the micro-mechanism of acicular ferrite nucleation induced by inclusions. The study and provide a theoretical basis for the development of new type pipeline steel with high strength and toughness. 


\section{Research on the Acicular Ferrite Nucleation Induced by the In-situ Reaction Inclusions in Welding Heat Affected Zone}

For the formation of acicular ferrite in the pipeline steel welding heat affected zone in high heat input welding conditions, the non-metallic inclusions need higher thermal stability. Ti oxides are mainly studied at present. Study has shown that when heat input reaching $80 \mathrm{~kJ} / \mathrm{cm}$, the acicular ferrite in $\mathrm{Ti}_{2} \mathrm{O}_{3}$ as nucleation exists in the coarse grain zone [3]. Acicular ferrite nucleation depends on the kinds of inclusions, but also associates with the number and size of inclusions. Research has shown that the acicular ferrite is easy to nucleate at inclusions only when the number range of inclusions is from $1.3 \times 10^{7}$ to $1.0 \times 10^{6}$ per $\mathrm{mm}^{3}$ and the size range of inclusions is from 0.25 to $0.80 \mu \mathrm{m}$ [4]. According to the median of the range, the needed oxygen content for the formation of the ideal number endogenous $\mathrm{Ti}_{2} \mathrm{O}_{3}$ inclusions is $0.0088 \%$. However, in practice only when the oxygen content is less than $0.0003 \%$ [5,6], Ti oxides are advantageous to precipitate as $\mathrm{Ti}_{2} \mathrm{O}_{3}$, which is prior to the TiN precipitation. The endogenous $\mathrm{Ti}_{2} \mathrm{O}_{3}$ of ideal number is very difficult to obtain by the in-situ reaction method using Oxides metallurgy. At present, for the in-situ reaction inclusions, the size of more than $1 \mu \mathrm{m}$ accounts for a large proportion, and the size and the distribution of the in-situ reaction inclusions are not uniform. Consequently, the size of the in-situ reaction inclusion is difficult to control.

\section{Research on the Acicular Ferrite Nucleation Induced by the Formed Inclusions after the Micro-alloying in Welding Heat Affected Zone}

\section{Composite Micro-alloying of $\mathrm{Nb}$ and $\mathrm{Ti}$}

In HSLA steels, the composite addtion of $\mathrm{Nb}$ and $\mathrm{Ti}$ can inhibit the rapid growth of grains in HAZ and can induce intragranular acicular ferrite to nucleate and grow around the inclusions containing $\mathrm{Nb}$ and $\mathrm{Ti}$ elements, which can segment grain, refine microstructure and improve the impact toughness $[7,8]$.

\section{Composite Oxides Micro-alloying of $\mathrm{Al}, \mathrm{Ti}, \mathrm{Mg}$ and $\mathrm{Zr}$}

The use of $\mathrm{A} 1, \mathrm{Ti}, \mathrm{Mg}$ and $\mathrm{Zr}$ alloy oxides or their composite oxides micro-alloying can promote the nucleation of the intragranular acicular ferrite and can segment the original austenite grains in the interior of the coarse austenite grains effectively, which can improve the toughness of HAZ significantly $[9,10]$. Coarse grained region microstructure are the coarse grain boundary ferrite and intragranular acicular ferrite in the HSLA steel of not containing zirconium, as shown in Fig. 1 (a) [11]. With Zirconium content increasing, the amount of acicular ferrite in the coarse grained region also increases. When Zirconium mass fraction is $0.01 \mathrm{wt} \%$, the number of acicular ferrite is the largest, as shown in Fig. 1 (b).

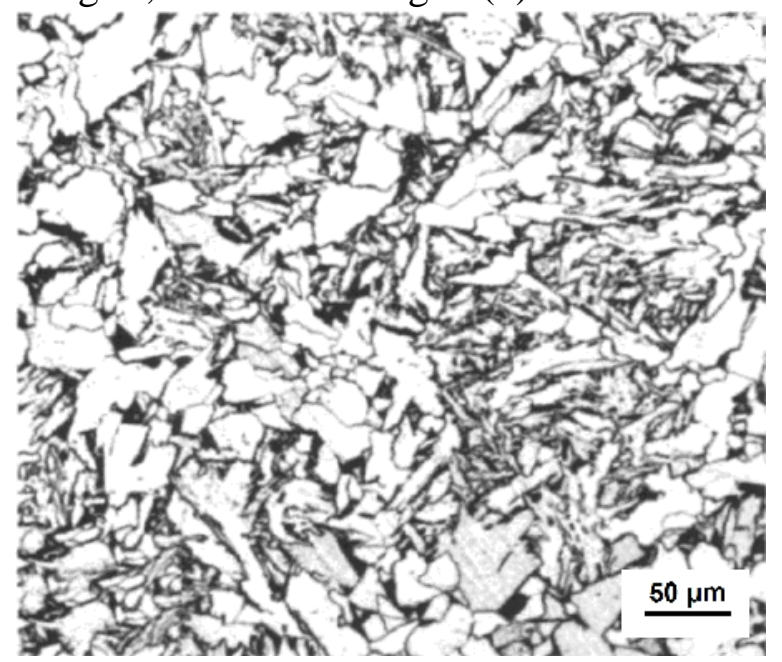

(a) HSLA steel of no $\mathrm{Zr}$

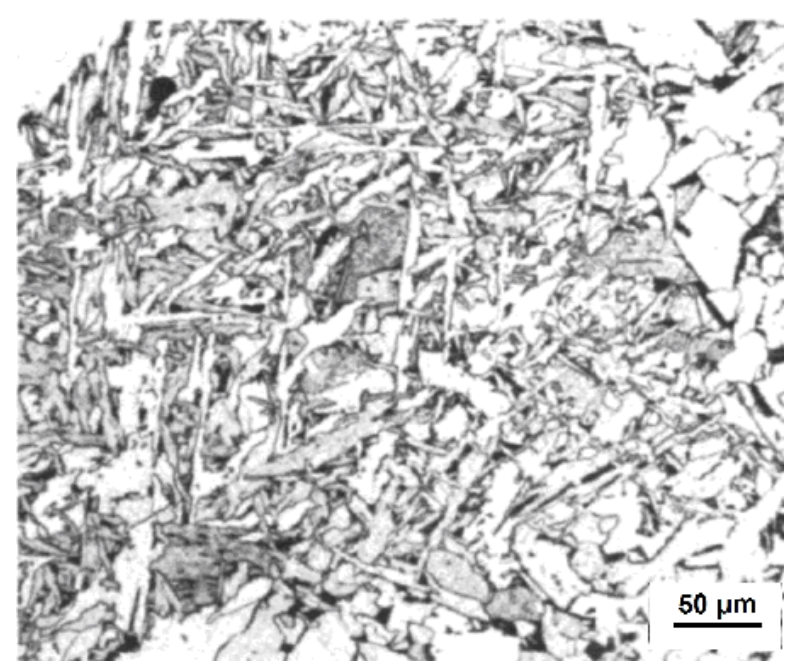

(b) HSLA steel of containing $0.01 \mathrm{wt} \% \mathrm{Zr}$

Fig.1 Microstructure of $\mathrm{Zr}$-Ti steel in welding coarse grained region $(100 \mathrm{~kJ} / \mathrm{cm}$ of energy input) 


\section{Micro-alloying of Ca and Mg}

$\mathrm{Ca}$ and $\mathrm{Mg}$ desulfurization technology can significantly improve the morphology and distribution of the sulfide and oxide inclusions, thus can improve steel toughness anisotropy. The addition of $\mathrm{Ca}$ and $\mathrm{Mg}$ to the Ti micro-alloyed steels can refine austenite by increasing the number of inclusions. The medium-scale austenite grain can prevent the formation of widmanstatten ferrite and polygonal ferrite and promote the formation of intragranular ferrite [12]. Therefore, the reasonable use of $\mathrm{Ca}$ and $\mathrm{Mg}$ in the micro-alloyed pipeline steels, on the one hand, can further increase the strength and toughness of the substrate by improving the morphology and distribution of the inclusions, and on the other hand, can improve the strength and toughness of HAZ through the effective refinement and control of the microstructure in the high heat input welding HAZ. Compared with the traditional way of improving the strength and toughness of the high heat input welding HAZ only by Ti element micro-alloying, this way is more favorable to the comprehensive performance of the material.

\section{Research on the Micro-mechanism of Acicular Ferrite Nucleation Induced by Inclusions}

Currently, the mechanisms of prompting acicular ferrite nucleation are mainly as follows.

1. The Stress-Strain Energy Mechanism. In the cooling process of weld thermal cycle, the shrinkage degree of the non-metallic inclusions and austenite is different, which result in the formation of a large area of high stress-strain energy region at the interface. The formation of acicular ferrite can reduce stress-strain energy effectively [13].

2. The Minimum Mismatch Mechanism. The lattice constants of non-metallic inclusions and acicular ferrite are very close. They have the smaller mismatch, so the acicular ferrite are easy to nucleate and grow around these inclusions [14].

3. The Local Composition Change Mechanism. There are a lot of anode vacancy at the center of non-metallic inclusions, which can absorb the Mn elements in the matrix. Consequently, Mn rich region is formed in the center of the inclusions, and Mn depleted zone is formed in the edge of the inclusions, where is the acicular ferrite induced to nucleate and grow [15].

4. The Inert Interface Energy Mechanism. The formation of the inert interface between non-metallic inclusions and matrix can reduce the nucleation threshold of the acicular ferrite, and make it nucleate and grow easily in the inert interface [16].

These four kinds of acicular ferrite nucleation mechanism exist mutual contradictions to each other. Different inclusions have different mechanism.

\section{Conclusions}

The acicular ferrite nucleation induced by inclusions in pipeline steel welding heat affected zone is researched in this paper, including the acicular ferrite nucleation induced by the in-situ reaction inclusions, the acicular ferrite nucleation induced by the formed inclusions after the micro-alloying and the micro-mechanism of acicular ferrite nucleation induced by inclusions.

(1) At present, for the in-situ reaction inclusions, the size of more than $1 \mu \mathrm{m}$ accounts for a large proportion, and the size and the distribution of the in-situ reaction inclusions are not uniform. Consequently, the size of the in-situ reaction inclusion is difficult to control.

(2) The use of $\mathrm{A} 1, \mathrm{Nb}, \mathrm{Ti}, \mathrm{Ca}, \mathrm{Mg}$ and $\mathrm{Zr}$ alloy oxides and or their composite oxides micro-alloying can promote the nucleation of the intragranular acicular ferrite and can segment the original austenite grains in the interior of the coarse austenite grains effectively, which can improve the strength and toughness of the high heat input welding HAZ significantly.

(3) Currently, the mechanisms of prompting acicular ferrite nucleation are mainly the stress-strain energy mechanism, the minimum mismatch mechanism, the local composition change mechanism and the inert interface energy mechanism. These four kinds of acicular ferrite nucleation mechanism exist mutual contradictions to each other. Different inclusions have different mechanism. 


\section{Acknowledgments}

This work was supported by the Liaoning Province Natural Science Fund Project (No. 2014020097), the Project for Liaoning Provincial Scientific Research in University of China (No. L2014475) and the Open Subject Fund of the State Key Laboratory of Rolling and Automation of NEU, China (No. 2009003).

\section{References}

[1]X.H. Lin, B.N. Qian, X.M. Guo, Development of submerged arc welding wires for high performance pipeline steel, J. of Iron and Steel Research, International. 4 (2003) 73-76.

[2]F.X. Huang, Research on internal circumferential automatic welding equipment and process for long distance pipeline with big size, Tianjin University. (2009) 6-7.

[3]W. Shu, X.M. Wang, S.R. Li, Nucleation and growth of intragranular acicular ferrite and its effect on grain refinement of the heat-affected-zone, Acta Metallurgica Sinica. 4 (2011) 435-441.

[4]D.M. Liang, Z.Y. Zhu, L.X. Zhou, Acicular ferrite and its heterogeneous nucleation mechanism in steels, Acta Metallurgica Sinica. 12 (2011) 105-111.

[5]J.L. Li, Y.T. Pan, The formation of intragranular ferrite in simulated heat-affected zone, ISIJ International. 8 (1995) 1027-1033.

[6]J.H. Qi, Investigation of Ti-deoxidized products in high grade pipeline steel and research on nucleation mechanism of IGF, Wuhan University of Science and Technology, Wuhan, 2009.

[7]J.L. Li, Y.T. Pan, Microstructure and toughness of the simulated HAZ in Ti and Al killed steels, Scientific Engineering. 2 (1991) 109-111.

[8]W. Yan, Y. Shan, K. Yang, Effect of Ti and Ni inclusions on the impact toughness of low-carbon microalloyed steel, Metallurgical and Materials Transactions. 37A, 7 (2006) 2147-2158.

[9]M. Chen, C.S. Wu, M. Yang, Response of second phase particle in Ti-V-Nb microalloyed steel during weld thermal cycles, Acta Metallurgica Sinica. 2 (2003) 148-154.

[10]T. N. Baker. Processes, Microstructure and properties of $\mathrm{V}$ anadium microalloyed steels, Materials Science and Technology. 9 (2009) 1083-1107.

[11]W.R. Xia, Effect of zirconium treatment on CGHAZ microstructure and properties of large heat input welding to low alloy steels, Iron \& Steel. 4 (2011) 76-81.

[12]W.H. Hu, J.H. Ye, J.W. Jin, Experiment and application of SiCaBa complex deoxidizer, Wide and Heavy Plate. 5 (2003) 9-10.

[13]S. Court, A. G. Pollard, Weld metal microstructure in carbon manganese deposits, C. The International Conference on Quality and Reliability in Welding, Hangzhou, China. (1984) 201-206.

[14]A. R. Mills, G. Thewlis, J. A. Whiteman, Nature of inclusions in steel weld metals and their influence on formation of acicular ferrite, Materials Science and Technology. 3 (1987) 1051-1061.

[15]J. M. Gregg, H. K. D. H. Bhadeshia, Solid-state nucleation of acicular ferrite on minerals added to molten steel, Acta Materialia. 2 (1997) 738-748.

[16]R. A. Ricks, P. R. Howell, G. S. Barritte, The nature of acicular ferrite in HSLA steel weld metals, J. of Materials Science. 3 (1982) 732-740. 